\title{
DOES THE FEDERAL \\ CONSTITUTIONAL COURT RULING MEAN \\ THE GERMAN FINANCIAL MARKET \\ IS EFFICIENT?
}

Bachar Fakhry ${ }^{1}$, Christian Richter ${ }^{2}$

EUROPEAN JOURNAL OF BUSINESS SCIENCE

${ }^{1}$ University of Lahore, Pakistan

${ }^{2}$ German University in Cairo, Egypt

Volume 4 Issue 2

ISSN 2336-6494

www.ejobsat.com

\begin{abstract}
Following the landmark ruling by the German Federal Constitutional Court in Karlsruhe on $7^{\text {th }}$ February 2014 in which they endorsed the efficient market hypothesis, we present evidence on the efficiency of the German financial market. Introducing a new variance bound test based on the Component-GARCH model of volatility to analyse the long- and short-runs effects on the efficiency of the German financial market, we test the price volatility of four markets: DAX stock index, German sovereign debt index as provided by Barclays and Bloomberg, Euro gold index by the World Gold Council and Euro currency index by the Bank of England. Our use of the Component-GARCH-T model highlight two key contributions, the first being the analysis of the efficiency of the market in the long and short runs. However, a more important contribution is the result of our variance bound test highlight the relatively strong acceptance of the efficient market hypothesis in both the short and long runs in all the observed financial markets. It must be stated our research is of importance to researches in both applied finance and portfolio management. The influencing question of what moves specific markets is crucial to market participants seeking market alpha for their investments strategies and portfolio optimisations.
\end{abstract}

\section{KEY WORDS}

EMH, volatility tests, C-GARCH-T, financial markets, gold market

\section{JEL CODES}

B13, B21, C12, G14, G15, H63 


\section{INTRODUCTION}

The question of what moves prices in the financial market is in itself not a new one. Recently, this debate gained new ground due to the recent financial crises which started in mid-2007. Therefore, the landmark ruling by the German Federal Constitutional Court in Karlsruhe on $7^{\text {th }}$ February 2014 in which they endorsed the efficient market hypothesis per Winkler (2014) is interesting on many levels. In a way, this highlights the question does the ruling mean that the German financial market is efficient? Furthermore, it raises an issue if the efficient market hypothesis is the key explanation of the price movement in the financial market then are the criticisms, as noted by Ball (2009) and Fakhry (2016), in the aftermath of the crises justified? The main question of what moves financial markets is important for researchers in the field of applied finance and portfolio manager, due to it being the underlining factor in investment decisions and portfolio optimisation. One of the key reasoning is that it is crucial for market participants wanting alphas for their investments decisions and portfolio optimisations.

Perhaps an explanation of the efficient market hypothesis or EMH would be ideal at this point. The EMH was developed thru the contribution of prominence articles by Fama and Malkiel such as: Malkiel (1962), Fama (1965), Malkiel and Fama (1970). At the basic level, the EMH hypothesize, as proposed by Malkiel (1962) and Fama (1965), that the price of any asset must immediately reflect fundamental information regarding the asset. The assumption is that market participants behave in accordance with the theory of perfect competition which is based on an idealise world where market participants are rational, risk averse and profit maximisers. Of course, recent events have illustrated that this is not always the case as Ball (2009) and Fakhry (2018) have shown. Therefore, there is a need to include behavioural finance in the pricing of any asset. The key argument underpinning behavioural finance is as put so elegantly by Thaler (2015, p.4) market participants are homo sapiens and not homo economicus, hence as stated by Bernard Baruch: "What is important in market fluctuations are not the events themselves, but the human reactions to the events." (Lee et al., 2002, p. 2277)

A key factor in the efficiency of the market is the differentiation between long and short run price volatility behaviour. As suggested by De Bondt (2000), the price tends to deviate from the fundamental value in the short run. However, the price usually reverts to the fundamental value in the long run. This is more obvious during an asset price bubble; as hinted by Blanchard and Watson (1982) and Barlevy (2007). Essentially an asset price bubble is a rapid upwards pressure on the price, eventually causing systematic downwards pressure to correct the price. Often leading to a crash in the prices where the price is under massive downwards pressure. In the long run, the market could return to the fundamental price and hence be "efficient" or it could collapse. The price movements are driven by market participants' reaction to events and information which differ and may be asymmetric in the short-run and long-run.

In order to analyse the different impacts from the short and long run on the efficiency of the German financial market, we change the variance bound tests of Fakhry and Richter (2015, 2016a, 2016b) and Fakhry et al. (2017) to use an asymmetrical variant of the C-GARCH model proposed by Engel and Lee (1999). This will allow us to distinguish between the long and short run efficiency. We also contribute by using the Euro currency index and German All Maturity sovereign debt index obtained from the Bank of England and Barclays Bank plc respectively. In addition, we use the DAX stock index. Since Germany has the second largest gold reserve and is the fourth biggest consumer of gold according to the World Gold Council, we also use the Euro gold index obtained from the World Gold Council.

Our findings indicate that unlike previous studies conducted using the variance bound test e.g. Fakhry and Richter (2015, 2016a), 
we found evidence suggesting that the German financial market is efficient. All four observed German markets: equity, gold, sovereign debt and foreign exchange were efficient in both the long and short runs. This suggests that the differentiation between the short and long run is limited in the case of the German financial market. However, another possible explanation is the stability state argument of Fakhry (2016). Fakhry (2016) hints that during large observations containing both high and low volatile periods, the periods could cancel each other out leading to the market appearing to be stable and efficient. This is usually the case in the long run as argued by De Bondt (2000). However, as argued Engle and Lee (1999), in the short run the market is more volatile and reactive; thus should reflect an inefficient market. There is a clue in the previous statement, a reactive market can sometime lead to a false state of stability which gives the impression of an efficient market, especially over a long period of observation.

Our two key contributions is that we use the component GARCH-T to analyse the long and short run efficiency of the market. Thus leading to our main contribution, namely that the results defy the conventional wisdom in that we found that the German financial market seems to be efficient in both the long and short runs.

Furthermore we also contribute via the data we use. although previously many have used stock and FX indices to observe the efficiency of the financial markets, yet the use of sovereign debt and gold market indices has been limited in the area of financial econometrics in general. The second contribution is that we analyse the efficiency of the Euro currency index as obtained from the Bank of England which have also been limited.

This article is structured in the following way. Firstly, we will briefly and critically review the recent empirical literature on the EMH, behavioural finance theory and component GARCH model. This will lead to the methodology which will describe specification of the variance bound test and underlying asymmetrical component GARCH models. Sections four and five presents the data and empirical results. Finally, section 6 concludes.

\section{LITERATURE REVIEW}

The Literature review is divided into three key subsections: a review of the empirical evident on the EMH, behavioural finance theory and the Component GARCH model. This article will not review the theories and tests underpinning the EMH and behavioural finance theory, see Fakhry (2016) and Fakhry (2018) for a critical review of the theories and tests. The crucial factor is the differentiation of the long run and short run on the price volatility which impact the efficiency of the market.

\subsection{Review of the Efficiency of the Markets}

The empirical evidence of the past few years have illustrated that markets are not efficient during a period of highly volatile and reactive environment as highlighted by recent studies in the sovereign debt market by Fakhry and Richter. In a series of studies into the efficiency of the sovereign debt market, see Fakhry and Richter (2015, 2016a, 2016b), they found that in general market participants reacted to events rather than fundamental information during the recent financial and sovereign debt crises. A similar point was illustrated by Fakhry et al. (2017). However, these studies also highlighted some evidence of efficiency during several periods in several markets. Conversely, although Fakhry and Richter (2015, 2016a) provided mixed evidence of the efficiency of the German Bund market. In truth, the evidence was pointing to an inefficient market in the general sense; since in theory any market cannot be partly efficient.

The evidence in the stock market is also mixed as illustrated by several recent studies 
(i.e. Borges, 2010; Panagiotidis, 2010; Onali and Goddard, 2011; Todea and Lazar, 2012; Sensoy and Tabak, 2015; Singh et al., 2015). Conversely, Borges (2010) found a split in the European stock markets with the Greek and Portuguese rejecting and the western European countries including Spain accepting the weak form EMH. Also finding that the German market does accept the weak form of the EMH. Interestingly, Sensoy and Tabak (2015) studying the impact of long-time memory on the efficiency of the European Union stock markets during the recent financial and sovereign debt crises found mixed evidence. This seem to be backing the evidence found in the sovereign debt market by Fakhry and Richter (2015, 2016a, 2016b) and Fakhry et al. (2017).

In a way, the recent evidence on the efficiency of the FX market is similar to the previous two markets in that it is mixed see (Ahmad et al., 2012; Lee and Sodoikhuu, 2012; Boboc and Dinică, 2013; Mele, 2015). Lee and Sodoikhuu (2012) analysed the impact of market strategies on the efficiency of the FX Market, finding that in general the three observed FX markets are efficient. Conversely, transaction costs do have a greater impact on the efficiency of the FX market. A key finding in accordance with our article is that the euro/dollar FX rate is efficient. Mele (2015) find that arbitrage opportunities do exist for longer periods in the FX market, therefore violating one of the fundamental rules underpinning the EMH: arbitrage opportunities don't exist for long periods. By default, this means that the FX market is inefficient. The results conflict with that of Lee and Sodoikhuu (2012) in illustrating that the leading FX markets, including the Euro, are inefficient.

Like the other markets, the limited recent empirical evidence for the efficiency of the gold market seem to be hinting at an inefficient market. Although the empirical evidence is not direct testing the EMH, the literature is concentrating on a weak form of efficiency by using two methods. The first is cointegration as use in Narayan et al. (2010) and Zhang and Wei (2010), the argument is if the market has a cointegration relationship with other markets than the market is regarded as inefficient. Narayan et al. (2010) found that the gold market has a cointegration relationship with the oil market. Zhang and Wei (2010) also found a strong relationship between the gold and oil markets. The second is multifractal as use in Wang et al. (2011), the argument is that if the trend in the market is unexplained by a single factor then the market is regarded as inefficient. However, Wang et al. (2011) seem to be hinting at a rather mixed evidence with the gold market appearing to be efficient during upward trending periods and inefficient during downward trending periods. Mali and Mukhopadhyay (2014) provide further evidence of the multifractal nature of the gold market in the Indian, Chinese and Turkish markets therefore these markets are regarded as inefficient.

\subsection{Brief Review of the Alternative Theory of Asset Pricing: Behavioural Finance}

As we have seen the recent empirical evidence on the efficiency of the market is not strong, Hence there is a need to include the behavioural finance theory for a complete picture of financial asset pricing. So we will analyse the empirical evidence on key behavioural factors in recent years.

In studies by Fakhry et al. (2017) and Masood et al. (2018), they found evidence of overreacting in the sovereign debt market. The Greek market is relatively small in comparison with the size of the eurozone market, hence the Eurozone crisis was based on overreacting market participants. Also as hinted by Fakhry (2018), during the financial crisis market participants fleeing from the equity markets and mortgage backed securities were underreacting in the sovereign debt market, there is a pattern of behaviour during any flight top safety that tend to lead to an underreaction. Conversely, as Ball (2009) points out there was a hint of underreaction to the information underpinning the mortgage back securities during the asset bubble of the mid-2000s.

Analysing the impact of the Tohoku Tsunami of 2011 on the Japanese financial market, 
Fakhry et al. (2017) found overreaction in the equity, FX and sovereign debt market during the immediate aftermath. This is in line with previous studies like Maierhofer (2011), Luo (2012), Parker and Steenkamp (2012) and Ferreira and Karali (2015) who found no impact other than in the immediate aftermath. Thus hinting that an overreaction is nearly always short lived during extreme events.

Another behavioural factor often observed is herding, Nofsinger and Sias (1999) characterized this phenomena as trading in the same direction by a group of investors for a period of time. This is often the case during in extreme conditions such as bubbles as illustrated by Jiang et al. (2010), Sornette and Cauwels (2015) and Gerlach et al. (2018) and crashes as highlighted by Brunnermeier (2009) and Economou et al. (2011) during flights.

\subsection{Review of Long/Short Run Volatility}

As stated by Pastor and Stambaugh (2012), conventional wisdom dictates there is a different between the long and short run. Generally, markets are less volatile in the long run due to being less perceptive to shocks; hence they are increasingly stable. As Engle and Lee (1999) states volatility is greater in the short horizon than in the long horizon. This indicates a more rapid short run volatility mean reversion than in the long run as hinted by Engle and Lee (1999). Per Colacito et al. (2011), another important principle often made in economics is the existence of different long and short run sources affecting volatility. Additionally, as De Bondt (2000) hints the price reverts to the fundamental value in the long run. This means that the factors effecting the price and hence price volatility in the short and long runs are different. Effectively what De Bondt (2000), Pastor and Stambaugh (2012) and many others like Engle and Lee (1999) are hinting is the reaction of markets participants tend to deviate with time. Another factor, suggested by Engle and Lee (1999), is the different impact from the leverage effect and market risk premium on the market in the short and long run. In a paper written as part of a book in honour of Clive Granger, Engle and Lee (1999) extended the GARCH model to account for the permanent (long run) and transitory (short run) components of volatility deriving the component GARCH model (aka CGARCH). In this section, we will review the empirical evidence on the $\mathrm{C}-\mathrm{GARCH}$ model.

Recent empirical evident for the C-GARCH model seem to agree with the general conception that financial market volatility differentiate between long and short runs. Much of the literature is concern with the volatility in the stock market. Guo and Neely (2006) found evident consistent with Engle and Lee (1999) suggesting that long-run volatility better determines the international conditional equity premium than the short run volatility. Adrian and Rosenberg (2008) interprets the shortrun volatility component as a measure of financial constraints tightness, while the long run volatility component is related to business cycle risks. However contrary to the accepted wisdom, Pastor and Stambaugh (2012) found that in accounting for predictor imperfection stock markets are more volatile in the long run. $\mathrm{Du}$ and $\mathrm{Hu}$ (2014) analysing the impact of the long run component in FX volatility on the stock market returns found that it does have explanatory power in determining the stock returns.

Analysing the Eurozone sovereign debt market, Sosvilla-Rivero and Morales-Zumaquero (2012) found a different between both volatility components. In general, the permanent component exhibited long memory while the transitory component exhibited short memory. They highlight that shocks are of higher importance than transitory shifts in the Eurozone sovereign debt market. Furthermore, they hint at a familiar split between the core and peripheral Eurozone countries in the transitory shifts with respect to the degree of policymakers' credibility and public finance's stability. 


\section{METHODOLOGY}

The main aim of this paper is to extend the variance bound test of Fakhry and Richter (2015) and Fakhry and Richter (2016a) to analyse the efficiency of the markets in the long and short runs. We proposed a new variance bound test by extending Fakhry and Richter (2016a) using an asymmetrical C-GARCH, proposed by Engle and Lee (1999), variant of the variance bound test proposed by Shiller $(1979,1981)$. We use the $5 \%$ critical value $F$-statistics to test the efficient market hypothesis. As with Fakhry and Richter (2015, 2016a, 2016b) and Fakhry et al. (2017), we follow the pre-requisite steps advocated by Shiller $(1979,1981)$.

1. As illustrated by Shiller (1981), the key factor underlying any variance bound test is the variance calculation. We model the datasets in our test as a time varying lagged variance of the price using equation 1 . We used the 5-lagged system, as oppose to the 20-lagged system advocated by Fakhry and Richter (2015).

$$
\lim _{t \rightarrow T} \operatorname{var}\left(\text { Price }_{t}\right)=\frac{\sum_{q=1}^{Q}(\text { Price }-\mu)^{2}}{Q} .
$$

2. The first order autoregressive model estimates the residuals in the econometric model underpinning the test as illustrated by equation 2 and 3 :

$$
\begin{gathered}
\operatorname{var}\left(\text { Price }_{t}\right)=a+b_{1} \operatorname{var}\left(\text { Price }_{t-1}\right)+\mu_{t}, \\
\mu_{t}=\tau \mu_{t-1}+\varepsilon_{t} .
\end{gathered}
$$

3. Estimate the first order asymmetrical CGARCH $(1,1)$ model to obtain the long run and short run volatility coefficients. It is worth remembering that the $\mathrm{GARCH}(p$, $q)$ model as proposed by Bollerslev (1986) is written as equation 4 where $h_{t}=\sigma_{t}^{2}$ and $k_{t}=\varepsilon_{t}^{2}$ :

$$
h_{t}=\omega+\alpha_{p} k_{t-1}+\beta_{q} h_{t-1} .
$$

As suggested by Engle and Lee (1999), equation 4 can be slightly transformed into equation 5 where the dynamics of the structure of conditional variance can be illustrated:

$$
\left.h_{t}=\sigma^{2}+\left(\alpha_{p} k_{t-1}-\sigma^{2}\right)+\beta_{q} h_{t-1}-\sigma^{2}\right) .
$$

The issue is that $\sigma^{2}$ represents the unconditional long run variance. However as argued by Engle and Lee (1999), at the heart of this equation is the question of whether the long run volatility is truly constant over time. Surely, a more flexible specification where the long run volatility is allowed to evolve lowly in an autoregressive manner is a more appropriate model of volatility, given the empirical evidence on time varying and mean reverting volatility as stated by Engle and Lee (1999). A more flexible model would be equation 6 whereby $\sigma^{2}$ is represented by $m_{t}$, a time-varying long run model of volatility.

$$
\begin{gathered}
m_{t}=\omega+\rho_{p} m_{t-1}+\varphi_{q}\left(k_{t-1}-h_{t-1}\right), \\
\left(h_{t}-m_{t}\right)=\begin{array}{c}
\sigma^{2}+\left(\alpha_{p} k_{t-1}-m_{t-1}\right)+ \\
+\left(\beta_{q} h_{t-1}-m_{t-1}\right) .
\end{array}
\end{gathered}
$$

Hence, equation 6 is a stochastic representatives of the long run volatility otherwise known as the trend in volatility and equation 7 is the difference between the conditional volatility and trend, i.e. the long run volatility. Essentially equation 7 is the short run or transitory volatility.

In essence, this means the dynamics of the volatility components can be interpreted as in three steps. Firstly, the short run volatility component is mean reverting to zero at a geometric rate of $(\alpha+\beta)$ under the condition of $0<(\alpha+\beta)<1$. Secondly, as highlighted previously the long run volatility component evolves over time in an AR process; conversely if $0<\rho<1$ then it will converge to a constant level of $\frac{\omega}{1-\rho}$. The third step is based on the assumption that the long run volatility component has a slow rate of mean reversion than the short run volatility component; simply put, the long run volatility component is the more persistent of the two components meaning $0<(\alpha+\beta)<\rho<1$. 
We opt to use a single asymmetrical order one lagged C-GARCH model in our tests. Remember the short run volatility component is given by equation 7 . The TARCH model as defined by Zakoian (1994) is given by equation 8. Taking equation 8 , we could transform it to a single order asymmetrical C-GARCH model by subtracting the long run volatility from each term in the equation to give equation 9 . Notice how if the asymmetrical effect is zero the basic model collapses to a CGARCH model as illustrated by equation 7 . A key factor is that the asymmetrical effect is only added to the short run component of the C-GARCH model, see equation 9 . This is mainly due to the short life of the asymmetrical effect.

$$
\begin{gathered}
h_{t}=\alpha k_{t-1}+\beta h_{t-1}+\gamma k_{t-1} I \\
\left(h_{t}-m_{t}\right)=\sigma^{2}+\left(\alpha_{p} k_{t-1}-m_{t-1}\right)+ \\
+\left(\beta_{q} h_{t-1}-m_{t-1}\right)+ \\
+\gamma\left(k_{t-1}-m_{t-1}\right) I
\end{gathered}
$$

where $I= \begin{cases}0, & \varepsilon_{t} \geq 0, \\ 1, & \varepsilon_{t}<0 .\end{cases}$

As with Fakhry and Richter (2016a, 2016b), we also illustrate the impact of the asymmetrical effect on the efficiency of the market. The key is the $\gamma$ coefficient in equation 9 where $\gamma \neq 0$ then there is an asymmetrical effect; if $\gamma>0$ then there is a leverage effect meaning negative shocks have greater impact than positive shocks.

As noted by Engle and Patton (2001), there is a story within any member of the GARCH family of volatility models influenced by the coefficients in the transitory and permanent variance equations. Since as illustrated by Engle and Patton (2001), the market shocks and persistent are indicated by the coefficients $\alpha$ and $\beta$, respectively. Therefore, we can deduce that $\phi$ and $\rho$ indicate the long run market shocks and persistent, respectively.

The coefficients of the Component-GARCH model of volatility are also key to our variance bound test. As mentioned earlier in this section, we derive our EMH test by using the $f$ statistics; for our observed samples, the $f$ statistics at the $5 \%$ level is 1.96 . We calculate our test statistics using equation 10 and 11 as the short run and long run tests of efficiency respectively.

$$
\begin{aligned}
\text { EMH Test }_{\mathrm{SR}} & =\frac{(\alpha+\beta+\gamma)-1}{\text { std. dev. }(\operatorname{var}(x))} \leq \\
& \leq F \text {-statistics, } \\
\text { EMH Test }_{\mathrm{LR}} & =\frac{(\rho+\phi)-1}{\text { std. dev. }(\operatorname{var}(x))} \leq \\
& \leq F \text {-statistics. }
\end{aligned}
$$

By definition the market is efficient when the conditions as set in equations 10 and 11 are true. Theoretically, the market is only truly efficient when the EMH test statistics is equal to the $f$-statistic. Hence, we reject the null hypothesis for the EMH if the condition in equations are true but accept the null hypothesis of the market being too volatile to be efficient for anything else.

\section{DATA DESCRIPTION}

As stated previously, this paper analyses the three major German financial markets to establish whether the court ruling means they are efficient. With this in mind, we test the efficiency of the equity, FX and sovereign debt markets. As illustrated in, we opt to use the price on indices to reflect the German financial market. As with the norm, we choose to use a five-day week filling in the missing data with the last known price.

It must be noted that similar to all indices the four indices are based on weighted ratios of the components prices. The DAX consist of thirty of the largest listed companies on the German equity market each weighted by a given ratio. The Euro Currency Index ${ }^{1}$ is calculated on a

\footnotetext{
${ }^{1}$ For a description of the index and how it is calculated see the following Bank of England website: http://bankofengland.co.uk/statistics/pages/iadb/notesiadb/Effective_exc.aspx.
} 
daily basis by the Bank of England using the five major currencies with a weighted ratio: US Dollar, British Sterling, Japanese Yen, Swiss Franc and Swedish Krona. As hinted by the name, the German All Maturities Government Index consists of all the government bonds maturities weighted by a ratio. The Gold Price Index consist of all gold markets in the Eurozone indexed to $1^{\text {st }}$ January 1999.

\section{EMPIRICAL EVIDENCE}

As hinted earlier, the keys to the EMH test statistics are the coefficients to the variance equation of the volatility model and standard deviation of the observed dataset. Hence in essence the model of volatility estimated determines the statistics. In Fakhry and Richter (2015) and Fakhry et al. (2017), the estimated model was the GARCH. In Fakhry and Richter (2016a, 2016b), the model used was the GJRGARCH. The GJR-GARCH had the influential factor of allowing for the analysis of the asymmetrical effect on the EMH. We continue to use the asymmetrical effect in this paper, however we also analyse the effect of long and short runs on EMH. For this reason, we use the C-GARCH with an asymmetrical factor in the estimation of the coefficients. We test for overall, long run and short run efficiency. We also analyse the behaviour of the German financial market volatility.

Tab. 2: Model Settings

\begin{tabular}{lc}
\hline Option & Setting \\
\hline Optimisation Method & EViews Legacy \\
Legacy Method & Marquandt \\
Max Iterations & 5,000 \\
Convergence & 0.0001 \\
Coefficient Covariance Method & Ordinary \\
Starting Coefficient Values & EViews Supplied \\
Presample Variance & Backcast with \\
& parameter $=0.7$ \\
Derivative Method & Accuracy \\
\hline
\end{tabular}

In estimating the models, we used the settings in Tab. 2. However, with the error distribution,
A key issue with our variance bound test was the standard deviation of the DAX Index and Gold market variances which caused a problem with the EMH test statistics. We tried several methods to resolve the issue, the best solution was to divide the daily index price by 100 and 10 for the DAX and Gold prices respectively before calculating the five-day variance. we used a different distribution model for each dataset to get the best estimation: Equity (Normal), FX (GED), Sovereign Debt (Student's $t$ ) and Gold (Student's $t$ ). Crucially, the system environment may influence the estimation: Our system is running EViews 9.5 on a Windows 10 Pro, 6 cores CPU and 24 Gigabytes RAM computer $^{2}$.

A general summarization is the observation of a different in the behaviour of price volatility between the long and short runs in all three financial markets. It is to be noted that the volatility seems to be more persistence in the long run than the short run. However as argued by De Bondt (2000), the evidence seem to suggest that the market is reverting back to the fundamental value in the long run. A key explanation is persistency in market volatility can only be observed in the long-run, since the persistent is based on long memory behaviour as hinted by Engle and Lee (1999). However, the markets seem to be highly reactive in the short run. This appears to be in accordance with the accepted wisdom of volatility being greater in the short run than the long run as argued by Engle and Lee (1999) and Pastor and Stambaugh (2012). This is to be expected, since behavioural theories dictate that market participants react with greater intensity to news in the short run as hinted by Engle and Lee (1999). In effect this means that the effect of the reaction of the German market participants on financial market volatility is deviating with time as suggested by Engle and Lee (1999), De Bondt (2000) and Pastor and Stambaugh (2012).

\footnotetext{
${ }^{2}$ We tested on a different environment got slightly different estimation results.
} 
Tab. 1: Major German Financial Markets Indices

\begin{tabular}{lllll}
\hline Market & Equity & Foreign Exchange & Sovereign Debt & Gold \\
\hline Index & DAX & $\begin{array}{l}\text { Effective Exchange } \\
\text { Rate Index, Euro }\end{array}$ & $\begin{array}{l}\text { German all } \\
\text { Maturities Index }\end{array}$ & Gold Price Index, Euro \\
Source & investing.com & Bank of England & $\begin{array}{l}\text { Barclay Risk Analytics } \\
\text { \& Index Solutions Ltd. }\end{array}$ & World Gold Council \\
& & & from 31/12/1997 & from $29 / 12 / 1978$ \\
Period & from $02 / 01 / 1981$ & from 02/01/1975 & to 31/12/2016 & to 30/12/2016 \\
to $31 / 12 / 2016$ & to $31 / 12 / 2016$ & 4,958 & 9,916 \\
\hline
\end{tabular}

Note: ${ }^{*)}$ It must be noted that on the $24^{\text {th }}$ August 2016 the Barclay Risk Analytics and Index Solutions Ltd. was taken over by Bloomberg. So, the product is now known as Bloomberg Government bonds.
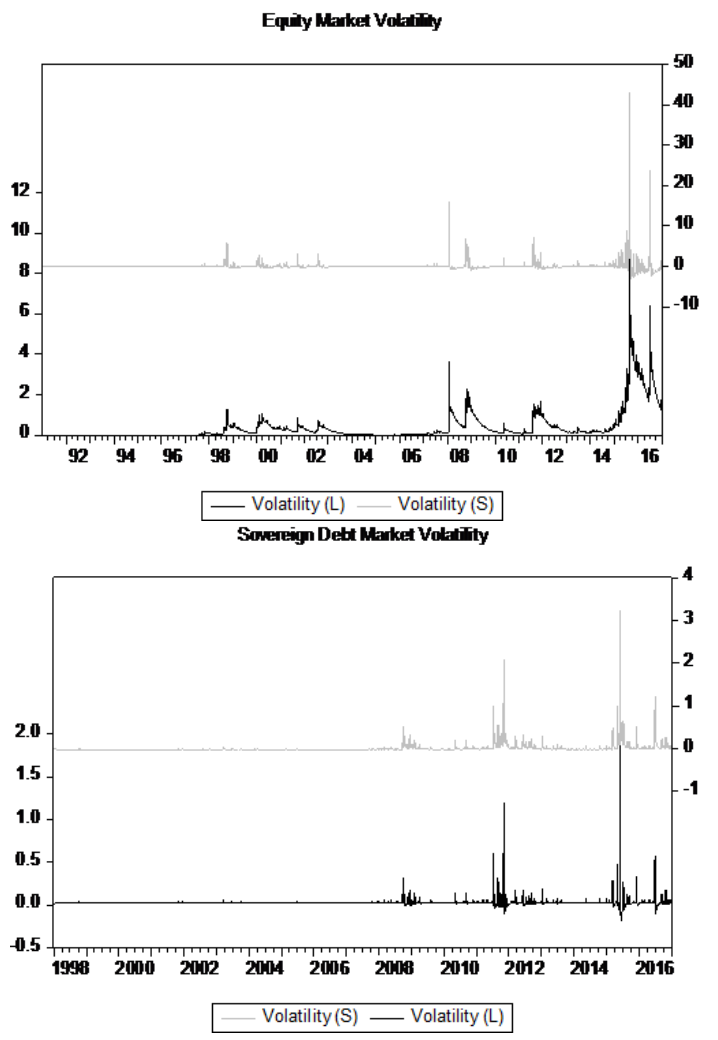

Fig. 1: German Financial Markets Volatility Components

The observed period is interesting because it highlights the different impact of major events on the long and short run volatility. Essentially, Fig. 1 highlights the impact from two key events on the German financial market, financial crises of late 2007 to 2016 . Whichever way you look at it, the financial crises seem to have a strong effect on the three observed markets. Conversely, the Brexit vote on $23^{\text {rd }}$ June 2016 extended the volatile period. Of cause the introduction

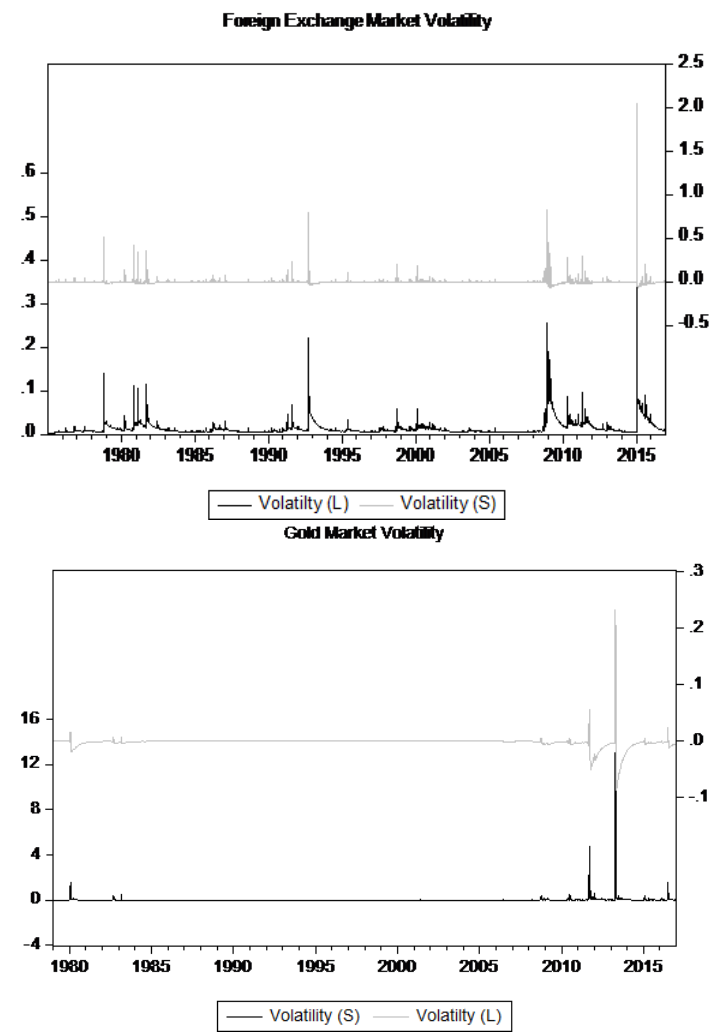

of the Euro on $1^{\text {st }}$ January 1999 is of significant interest to the German financial market, yet the evident from Fig. 1 seem to hint at a slight impact on the equity and FX markets but none on the sovereign debt and gold markets. However, it is worth remembering that these two markets are regarded as safe havens and the introduction of the euro was not regarded as a risk. Another possible explanation is due to the large impact of the financial and sovereign 
debt crises on these two markets, the volatility in these two markets deviated away. Remember a key theory of the GARCH/ARCH models as intended by Engle (1982) and Bollerslev (1986) is that volatility deviates over time, so a highly volatile event in the past becomes less influential with time on the observed dataset. The other major event is the aftermath of the re-unification of Germany in 1990 which seem to be highlighted in the FX market but not in the equity and gold markets. However, a key factor during that period could be the impact from Black Wednesday on $16^{\text {th }}$ September 1992 and the effect it had on the European Exchange Rate Mechanism (ERM).

The high $\rho$ coefficients in Tab. 2 seem to be indicating the presence of highly persistent permanent volatility in the equity and FX markets. On close inspection of Fig. 1, the reasoning becomes clear, both markets were at the heart of periods of constant highly volatile environment as illustrated in the previous paragraph. Market participants are highly reactive to events such as these. The second factor is the long-run effects of the introduction of the Euro and the recent financial and sovereign debt crises which contributed to the high persistent of volatility. It would seem that the recent crises were also a relevant contributory for the high persistency in the gold market. Conversely, Fig. 1 also explains the low volatility persistence in the sovereign debt market as illustrated by the $\rho$ coefficient of the market in Tab. 3 . In comparison to the other three observed markets, the sovereign debt market seemed to be relatively stable until the recent crises with only a few minor hikes in volatility. A possible explanation is generally during a period of economic and financial market upturn like the early to mid-2000s, market participants are less reactive and thus market volatility is less persistent. This leads to another explanation, during a period of increasing asset prices, market participants look for high return risky markets, in simple terms acting irrationally leading to a bubbled market. The sovereign debt market is generally regarded as a risk-free low earning market, especially the German market. As explained earlier, the short run volatility persistent tends to be generally low, a point in case are the observed $\beta$ coefficients of all four markets in Tab. 3. The coefficients seem to be hinting at very low volatility persistency in all four markets with coefficients of not greater than 0.708 .

As implied by Engle and Lee (1999), theory dictates over a long-time horizon market shocks tend to decay in ferocity. Thus, meaning that in the long run the effect of any event inducing high market shocks on prices become less relevant. This is observed in the equity, gold and FX markets as illustrated by Tab. 3 with the $\varphi$ coefficients pointing to a lower market shock in the long run. In effect the $\varphi$ coefficients are under 0.1 for all three markets hinting at a low sensitivity to market shocks. As Fig. 1 illustrates, all three markets suffered a significant hike in price volatility during the recent crises period plus the Brexit vote and the coefficients, greater than 0.2 , seem to be reflecting this hike. Mainly due to the timing and severity of a combination of events (i.e. the recent Eurozone sovereign debt crises and Brexit vote) and the German sovereign debt market status as the safe haven and liquid market in the Eurozone, the long run effect of the shocks in the sovereign debt market did not decay away given the time horizon as illustrated by the $\varphi$ coefficient at 0.186334 . In the short run, the high coefficient of 0.312428 is a sign of the market during the crises period.

A key observation made in Fakhry and Richter (2016a, 2016b) is that the asymmetrical effect has an impact on the efficiency of the market. As illustrated by Tab. 3, we observed a low $\gamma$ coefficient for all four markets with absolute value of no greater than 0.09 observed in the gold market. This does mean that there is a limited asymmetrical effect in each of the markets. The equity and gold markets display a negative $\gamma$ coefficient which means that negative shocks to the market have greater impact than positives shocks in the short run. As hinted by Black (1976), a key observation often made in the equity market is the negative correlation between returns and volatility. The limited leverage effect is a hint of this observation. The key word in there being limited, for an 
Tab. 3: Statistics for Variance Bound Test using Asymmetrical C-GARCH model

Equations:

(6) $\quad m_{t}=\omega+\rho_{p} m_{t-1}+\varphi_{q}\left(k_{t-1}-h_{t-1}\right)$

(9) $\quad\left(h_{t}-m_{t}\right)=\sigma^{2}+\left(\alpha_{p} k_{t-1}-m_{t-1}\right)+\left(\beta_{q} h_{t-1}-m_{t-1}\right)+\gamma\left(k_{t-1}-m_{t-1}\right) I$

$(10,11) \quad$ EMH Test $=\frac{\sum \text { coefficients }-1}{\text { std. dev. }(\operatorname{var}(\text { Price }))}$

\begin{tabular}{|c|c|c|c|c|}
\hline Market & Equity & Foreign Exchange & Sovereign Debt & Gold \\
\hline \multicolumn{5}{|l|}{ Mean Equation } \\
\hline$a$ & $\begin{array}{c}0.071782^{*} \\
(0.002136)\end{array}$ & $\begin{array}{c}0.009607^{*} \\
(0.000192)\end{array}$ & $\begin{array}{c}0.020584^{*} \\
(0.000678)\end{array}$ & $\begin{array}{c}0.005543^{*} \\
(8.41 \mathrm{E}-06)\end{array}$ \\
\hline$b$ & $\begin{array}{c}0.716483^{*} \\
(0.006919)\end{array}$ & $\begin{array}{c}0.736035^{*} \\
(0.003483)\end{array}$ & $\begin{array}{c}0.691017^{*} \\
(0.006640)\end{array}$ & $\begin{array}{c}0.719573^{*} \\
(0.001878)\end{array}$ \\
\hline$\mu$ & $\begin{array}{c}0.507201^{*} \\
(0.013024)\end{array}$ & $\begin{array}{c}0.306194^{*} \\
(0.006653)\end{array}$ & $\begin{array}{c}0.377432^{*} \\
(0.015129)\end{array}$ & $\begin{array}{c}0.375839^{*} \\
(0.000891)\end{array}$ \\
\hline \multicolumn{5}{|c|}{ Volatility Equation } \\
\hline$\omega$ & $\begin{array}{c}7.480590^{*} \\
(0.384085)\end{array}$ & $\begin{array}{c}0.029847 \\
(0.033685)\end{array}$ & $\begin{array}{c}0.026859 \\
(0.003366)\end{array}$ & $\begin{array}{r}-2.37 \mathrm{E}-05 \\
(2.16 \mathrm{E}-06)\end{array}$ \\
\hline \multicolumn{5}{|c|}{ Long-run Price Volatility } \\
\hline$\rho$ & $\begin{array}{c}0.999998^{*} \\
(6.43 \mathrm{E}-08)\end{array}$ & $\begin{array}{c}0.998977^{*} \\
(0.001167)\end{array}$ & $\begin{array}{c}0.847473^{*} \\
(0.023697)\end{array}$ & $\begin{array}{c}0.987450^{*} \\
(9.24 \mathrm{E}-04)\end{array}$ \\
\hline$\varphi$ & $\begin{array}{c}0.039161^{*} \\
(0.000976)\end{array}$ & $\begin{array}{c}0.087957^{*} \\
(0.022952)\end{array}$ & $\begin{array}{c}0.186334^{*} \\
(0.022307)\end{array}$ & $\begin{array}{c}0.008243^{*} \\
(0.002056)\end{array}$ \\
\hline \multicolumn{5}{|c|}{ Short-run Price Volatility } \\
\hline$\alpha$ & $\begin{array}{c}0.213435^{*} \\
(0.003626)\end{array}$ & $\begin{array}{c}0.359580^{*} \\
(0.019467)\end{array}$ & $\begin{array}{c}0.312428^{*} \\
(0.017036)\end{array}$ & $\begin{array}{c}0.453493^{*} \\
(0.020139)\end{array}$ \\
\hline$\gamma$ & $\begin{array}{r}-0.019528^{*} \\
(0.005517)\end{array}$ & $\begin{array}{c}0.062521^{*} \\
(0.007920)\end{array}$ & $\begin{array}{c}0.012089^{*} \\
(0.001591)\end{array}$ & $\begin{array}{r}-0.092895^{*} \\
(0.015680)\end{array}$ \\
\hline$\beta$ & $\begin{array}{c}0.707345^{*} \\
(0.005470)\end{array}$ & $\begin{array}{c}0.577842^{*} \\
(0.025604)\end{array}$ & $\begin{array}{c}0.675722^{*} \\
(0.017817)\end{array}$ & $\begin{array}{c}0.646091^{*} \\
(0.008971)\end{array}$ \\
\hline \multicolumn{5}{|l|}{ Model Statistics } \\
\hline Log Likelihood & $1,374.877$ & $20,161.730$ & $7,075.928$ & $28,617.290$ \\
\hline$R^{2}$ & 0.719687 & 0.712889 & 0.725742 & 0.751854 \\
\hline DW-Statistics & 2.156971 & 1.625504 & 1.575250 & 1.686794 \\
\hline ARCH Effects & 0.339560 & 0.028096 & 0.018395 & 0.526407 \\
\hline Jarque-Bera & $434,325.400$ & $22,946,634.000$ & $491,035.900$ & $3,280,997.000$ \\
\hline$\sigma^{2}$ & 1.193893 & 0.166384 & 0.317139 & 0.233287 \\
\hline \multicolumn{5}{|l|}{ Efficiency Tests } \\
\hline \multicolumn{5}{|c|}{ Long-run Efficiency } \\
\hline EMH Statistics & 0.032799 & 0.522490 & 0.106600 & 0.018462 \\
\hline Efficiency & Accept & Accept & Accept & Accept \\
\hline \multicolumn{5}{|c|}{ Short-run Efficiency } \\
\hline EMH Statistics & 0.082711 & 0.000343 & 0.000754 & 0.028673 \\
\hline Efficiency & Accept & Accept & Accept & Accept \\
\hline
\end{tabular}

Notes: The numbers in brackets are standard errors, *** indicated $10 \%$ significance level, $* *$ is $5 \%$ and $*$ is $1 \%$. 
explanation we need to look at the observed German equity and gold markets. It is highly possible that during the period before the onslaught of the recent global financial crises, both markets experienced one type of asymmetrical effect. However, the onslaught of the recent global financial crises changed the asymmetric effect. The positive and negative effects may have counter-balanced each other, hence leading to the near zero impact. Conversely, due to the timing and ferocity of the negative impact on the markets during the recent global financial crises, there is a limited leverage effect. The two remaining markets point to a limited positive asymmetrical effect hinting at positive shocks to the market having a greater impact than negative shocks in the short run. An explanation for the observations of positive asymmetrical effects could be found in a combination of the global status of both markets and the recent global financial environment. This added to the reversed of the combination effect underpinning the explanation of the observed limited leverage effect in the equity and gold markets means that the FX and sovereign debt markets exhibit slight positive asymmetrical effects.

A key measure of risk factors in the market is the standard deviation, essentially defined as the dispersion of the observed market prices around the expected market price. The standard deviation statistics from Tab. 3 seem to be hinting at a large dispersion from the expected price variance in the equity market with a $\sigma^{2}$ of approximately 1.194. A clue is in Fig. 1, both the long and short run volatilities hint at a large hike in the equity market during the recent financial crises which gives the impression of a large dispersion in the equity market. The FX market has a low standard deviation of approximately 0.166 , this is to be expected since the euro did not deviate from the expected value by much. Even during the Eurozone crises, the movement against the benchmark currencies was not that great in both the long and short runs, as hinted by Fig. 1. The sovereign debt market suffered from spikes in the volatility during the Eurozone crises which is indicated by the low standard deviation of 0.317 and the level of volatility in Fig. 1 . It must be noted that the German sovereign debt market is regarded as the risk-free benchmark market in the Eurozone, so the movement in the market was mainly due to runs in the Eurozone markets leading to upward pressures on the German sovereign debt market. And as the age old saying by Isaac Newton goes: "what goes up must come down" eventually, hence the normalisation of the sovereign debt market towards the fundamental long run value may have also been a factor in the moderate standard deviation. The same could be said about the gold market, remember the gold market is the global safe haven market. In essence, the gold market, similar to many other commodity markets, suffered a bubble reaction during the global financial crises. However, the low dispersion is a sign that the impact of the global financial crises did not impact the overall observation.

Essentially, our variance bound test is saying that for a market to be efficient it must be efficient in the short and long runs. As illustrated by Tab. 3, the significant of the variance bound test is the results seem to be hinting at the acceptance of the EMH in all the observed markets in both the short and long runs. The statistics are damming for behavioural finance with EMH statistics not greater than 0.6 , it must be remembered that these are well within the bound of 1.96 .

\section{CONCLUSION}

In this paper, we extended the work done by Fakhry and Richter in recent years to analyse the efficiency of the German financial market in the short and long runs. We differed from previous work by Fakhry and Richter in using a five-day variance calculation and the key indices of the German market. We used a Component GARCH including a threshold to obtain the short and long runs' volatility and coefficients for our EMH tests. 
Our results show that the German financial market is efficient in both the short and long runs. The results seem to be a damming rejection of the behavioural finance theory and an endorsement of the court ruling. However, as is the case with any test there are a number of factors to account for. The first and foremost is the observational period in all the market, if the period was based around the financial and sovereign debt crises then the results may have been different. The second is the volatility model, i.e. Component GARCH, underpinning our volatility tests could be a key factor in the acceptance of the EMH. It would be interesting to see if the German financial market was efficient around the crises period of the late 2000 s to early 2010s. Given that the results of Fakhry and Richter (2015, 2016a, 2016b) did found that the German market is generally inefficient during the crisis period.

Our main contribution, the methodology, is relevant in analysing the long and short run efficiency of the market and therefore making the optimal investment decision be it in an asset or as part of a portfolio. The results of our empirical study are important for researchers in the fields of applied finance and portfolio management. Additionally, the paper can be useful for portfolio managers and market participants in making investment decisions or portfolio optimisation.

In concluding, the results seem to suggest that the court case was right to endorse the EMH. However, we urge caution on rejecting the behavioural finance theory due to past empirical evidence suggesting that the German market is not always efficient.

\section{REFERENCES}

Adrian, T. and Rosenberg, J. 2008. Stock Returns and Volatility: Pricing the Short-Run and LongRun Components of Market Risk. The Journal of Finance, 63 (6), 2997-3030.

Ahmad, R., Rhee, S. G. and Wong, Y. M. 2012. Foreign Exchange Market Efficiency under Recent Crises: Asia-Pacific Focus. Journal of International Money and Finance, 31 (6), 1574-1592.

BALL, R. 2009. The Global Financial Crisis and the Efficient Market Hypothesis: What Have We Learnt? Journal of Applied Corporate Finance, 21 (4), 8-16.

Barlevy, G. 2007. Economic Theory and Asset Bubbles. Economic Perspectives, 31 (3), 44-59.

Black, F. 1976. Studies of Stock Market Volatility Changes. In Proceedings of the 1976 Meeting of the Business and Economic Statistics Section, American Statistical Association, pp. 177-181.

Blanchard, O. J. and Watson, M. W. 1982. Bubbles, Rational Expectations and Financial Markets. National Bureau of Economic Research, Working Paper No. 945.

Boboc, I.-A. and Dinic $\breve{A}$, M.-C. 2013. An Algorithm for Testing the Efficient Market Hypothesis. PLoS ONE, 8 (10).

Bollerslev, T. 1986. Generalized Autoregressive Conditional Heteroskedasticity. Journal of Econometrics, 31 (3), 307-327.
Borges, M. R. 2010. Efficient Market Hypothesis in European Stock Markets. The European Journal of Finance, 16 (7), 711-726.

Brunnermeier, M. K. 2009. Deciphering the Liquidity and Credit Crunch 2007-2008. The Journal of Economic Perspectives, 23 (1), 77-100.

Colacito, R., Engle, R. F. and Ghysels, E. 2011. A Component Model for Dynamic Correlations. Journal of Econometrics, 164 (1), 45-59.

Du, D. and Hu, O. 2014. The Long-Run Component of Foreign Exchange Volatility and Stock Returns. Journal of International Financial Markets Institutions and Money, 31 (1), 268-284.

De Bondt, W. F. M. 2000. The Psychology of Underreaction and Overreaction in World Equity Markets. In Keim, D. B. and ZiembA, W. T. (eds.). Security Market Imperfections in World Wide Equity Markets, pp. 65-89. Cambridge: Cambridge University Press.

Economou, F., Kostakis, A. and Philippas, N. 2011. Cross-Country Effects in Herding Behaviour: Evidence from Four South European Markets. Journal of International Financial Markets, Institutions and Money, 21 (3), 443-460.

Engle, R. F. 1982. Autoregressive Conditional Heteroscedasticity with Estimates of the Variance of United Kingdom Inflation. Econometrica, 50 (4), 987-1007. 
Engle, R. F. and Lee, G. G. J. 1999. A Long-Run and Short-Run Component Model of Stock Return Volatility. In Engle, R. F. and White, H. (eds.). Cointegration, Causality and Forecasting - A Festschrift in Honour of Clive W. J. Granger. Oxford: Oxford University Press.

Engle, R. F. and Patton, A. J. 2001. What Good is a Volatility Model? Quantitative Finance, 1 (2), $237-245$.

FAKHry, B. 2016. A Literature Review of the Efficient Market Hypothesis. Turkish Economic Review, 3 (3), 431-442.

FAKHRY, B. 2018. Impact of the Crises on the Efficiency of the Financial Market: Evidence from the SDM. KSP Books.

FAKhry, B. and Richter, C. 2015. Is the Sovereign Debt Market Efficient? Evidence from the US and German Sovereign Debt Markets. International Economics and Economic Policy, 12 (3), 339-357.

Fakhry, B. and Richter, C. 2016a. Testing the Efficiency of the Sovereign Debt Market using an Asymmetrical Volatility Test. Journal of Management and Training for Industries, 3 (2), $1-15$.

FAkhry, B. and Richter, C. 2016b. Testing the Efficiency of the GIPS Sovereign Debt Markets using an Asymmetrical Volatility Test. Journal of Economics and Political Economy, 3 (3), 524-535.

Fakhry, B., Masood, O. and Bellalah, M. 2017. Are the GIPS Sovereign Debt Markets Efficient During a Crisis? Journal of Risk, 19 (S1), 27-39.

FAmA, E. F. 1965. Random Walk in Stock Market Prices. Financial Analyst Journal, 21 (5), 55-59.

Ferreira, S. and Karali, B. 2015. Do Earthquakes Shake Stock Markets? PLoS ONE, 10 (7).

Gerlach, J.-C., Demos, G. and Sornette, D. 2018. Dissection of Bitcoin's Multiscale Bubble History from January 2012 to February 2018 [online]. Available at: https://arxiv.org/abs/1804.06261 [Accessed 2018, October 1].

Guo, H. and Neely, C. J. 2006. Investigating the Intertemporal Risk-Return Relation in International Stock Markets with the Component GARCH Model. Economics Letters, 99 (2), 371-374.

Jiang, Z.-Q., Zhou, W.-X., Sornette, D., Woodard, R., Bastiaensen, K. and Cauwels, P. 2010. Bubble Diagnosis and Prediction of the 2005-2007 and 2008-2009 Chinese Stock Market Bubbles. Journal of Economic Behavior and Organization, 74 (3), 149-162.

Lee, H. and Sodoikhuu, K. 2012. Efficiency Test in Foreign Exchange Market. International Journal of Economics and Financial Issues, 2 (2), 216-224.
Lee, W. Y., Jiang, C. X. and Indro, D. C. 2002. Stock Market Volatility, Excess Returns and the Role of Investor Sentiment. Journal of Banking \&6 Finance, 26 (12), 2277-2299.

Luo, N. 2012. The Impact of Natural Disasters on Global Stock Market: the Case of the Japanese 2011 Earthquake [online]. Available at: http:// library2.smu.ca/handle/01/24714\#.WWYR_YjysuU [Accessed 2018, February 19].

MAIERHOFER, S. 2011. 5 Worst Disasters How Did the Stock Market React? [online]. Available at: http://www.nasdaq.com/article/ 5-worst-disasters-how-did-the-stock-market-react-cm68124 [Accessed 2018, February 15].

Malkiel, B. G. 1962. Expectations, Bond Prices, and the Term Structure of Interest Rates. The Quarterly Journal of Economics, 76 (2), 197-218.

Malkiel, B. G. and Fama, E. F. 1970. Efficient Capital Market: A Review of Theory and Empirical Work. The Journal of Finance, 25 (2), 383-417.

Mali, P. and Mukhopadhyay, A. 2014. Multifractal Characterization of Gold Market: A Multifractal Detrended Fluctuation Analysis. Physica A: Statistical Mechanics and its Applications, 413, 361-372.

Masood, O., Aktan, B., Gavurová, B., Fakhry, B., TVAronavičIEnĖ, M. and MartinkUtėKauliené, R. 2018. The Impact of RegimeSwitching Behaviour of Price Volatility on Efficiency of the US Sovereign Debt Market. Economic Research (Ekonomska Istraživanja), 30 (1), 1865-1881.

Mele, M. 2015. On the Inefficient Markets Hypothesis: Arbitrage on the Forex Market. International Journal of Economics, 9 (2), 111-122.

Narayan, P. K., Narayan, S. and Zheng, X. 2010. Gold and Oil Markets: Are Markets Efficient. Applied Energy, 87 (10), 3299-3303.

Nofsinger, J. R. and Sias, R. W. 1999. Herding and Feedback Trading by Institutional and Individual Investors. Journal of Finance, 54 (6), 2263-2295.

Onali, E. and Goddard, J. 2011. Are European Equity Markets Efficient? New Evidence from Fractal Analysis. International Review of Financial Analysis, 20 (2), 59-67.

PAnAgiotidis, T. 2010. Market Efficiency and the Euro: the Case of Athens Stock Exchange. Empirica, 37 (3), 237-251.

Parker, M. and Steenkamp, D. 2012. The Economic Impact of the Canterbury Earthquakes. Reserve Bank of New Zealand Bulletin, 70 (3), 13-25.

Pastor, L. and Stambaugh, R. F. 2012. Are Stocks Really Less Volatile in the Long Run? The Journal of Finance, 67 (2), 431-478. 
Sensoy, A. and TABAK, B. M. 2015. Time-varying Long Term Memory in the European Union Stock Markets. Physic A, 436, 147-158.

ShILleR, R. J. 1979. The Volatility of Long-Term Interest Rates and Expectations Models of the Term Structure. The Journal of Political Economy, 87 (6), 1190-1219.

ShILlER, R. J. 1981. The Use of Volatility Measures in Assessing Market Efficiency. The Journal of Finance, 36 (2), 291-304.

Singh, P., Deepak, C. A. and Kumar, A. 2015. Revisiting Weak Form Efficiency of Major Equity Markets in Light of Global Financial Crisis: A Panel Data Approach. Asia-Pacific Finance and Accounting Review, 3 (1), 17-44.

Sornette, D. and Cauwels, P. 2015. Financial Bubbles: Mechanisms and Diagnostic. Reviews of Behavioral Economics, 2 (3), 279-305.

Sosvilla-Rivero, S. and Morales-Zumaquero, A. 2012. Volatility in EMU Sovereign Bond Yields: Permanent and Transitory Components. Applied Financial Economics, 22 (17), 1453-1464.
ThaleR, R. H. 2015. Misbehaving: The Making of Behavioural Economics. Penguin Random House.

Todea, A. and Lazar, D. 2012. Global Crisis and Relative Efficiency: Empirical Evidence from Central and Eastern European Stock Markets. The Review of Finance and Banking, 4 (1), 45-53.

Wang, Y., Wei, Y. and Wu, C. 2011. Analysis of the Efficiency and Multifractality of Gold Markets Based on Multifractal Detrended Fluctuation Analysis. Physica A: Statistical Mechanics and its Applications, 390 (5), 817-827.

Winkler, A. 2014. Rescues Violating the German Constitution: The Federal Court Decides on a Theory of Finance. LSE Financial Markets Group Special Paper Series, SP No. 231.

ZAKOIAN, J.-M. 1994. Threshold Heteroskedastic Models. Journal of Economic Dynamics and Control, 18 (5), 931-955.

Zhang, Y. and Wei, Y. 2010. The Crude Oil Market and the Gold Market: Evidence for Cointegration, Causality and Price Discovery. Resources Policy, 35 (3), 168-177.

\section{AUTHOR'S ADDRESS}

Bachar Fakhry, The University of Lahore, School of Accountancy and Finance, Lahore, Pakistan, e-mail: mbachar.fakhry@me.com

Christian Richter, German University in Cairo, Faculty of Management Technology, Department of Economics, New Cairo City, Egypt, e-mail: christian.richter@guc.edu.eg 